\title{
Morphological and Radiographic Studies on the Skull of Indian Blackbuck (Antilope cervicapra)
}

\author{
Estudios Morfológicos y Radiográficos del Craneo del \\ Antilope Negro (Antilope cervicapra) de la India
}

\author{
Om Prakash Choudhary* \& Ishwer Singh**
}

CHOUDHARY, O. P. \& SINGH, I. Morphological and radiographic studies on the skull of Indian blackbuck (Antilope cervicapra). Int. J. Morphol., 34(2):775-783, 2016.

SUMMARY: The phenotypic appearance of the head of animal species depends strongly on the shape of the skull. The present study has been carried out on morphological and radiographic characteristics of skull of the Indian Blackbuck. The skull comprised of cranial and facial bones. The cranial bones included occipital, sphenoid, ethmoid, interparietal, parietal, frontal and temporal. The occipital was a single bone surrounding the foramen magnum. The sphenoid was a single bone and situated between the occipital posteriorly and the ethmoid anteriorly. The ethmoid was a single bone laid ventral to the frontal and nasal bones. The interparietal was a small quadrilateral bone wedged in between the parietal anterio-laterally and the supraoccipital posteriorly. The parietal was a paired bone. The frontal bone was a paired and formed the roof of the cranial cavity. The occipital bone was roughly pentagonal in shape. The temporal was a paired bone and formed the part of the lateral wall of the cranial cavity. The facial bones included maxilla, premaxilla, palatine, pterygoid, nasal, lacrimal, zygomatic, vomer, turbinates, mandible and hyoid. The maxilla was a roughly triangular flat paired bone. The paired incisive bones were placed on the lower part of the face. The palatine was a paired bone. The pterygoid was a paired, small, slightly curved, flat plate of bone and situated on either side of the posterior nares. The nasal was a paired bone and formed the roof of nasal cavity. The lacrimal was a paired bone and located on the anterior margin of the orbit. The zygomatic was a paired bone and irregularly triangular in outline. The vomer was a single medial bone. The turbinate bone was delicate, scroll-like, complex bony plates, placed vertically in the nasal cavity, being attached to the lateral walls. The mandible was a paired bone. The hyoid bone was situated between the vertical parts of the rami of the mandible.

KEY WORDS: Blackbuck; Skull; Morphological; Radiographic; Cranial; Facial bones.

\section{INTRODUCTION}

The blackbuck (Antilope cervicapra) is an ungulate species of antelope native to the Indian subcontinent that has been classed as near threatened by IUCN since 2003, as its range has fallen precipitously during the $20^{\text {th }}$ Century. The blackbuck is protected under Schedule "I" of the Indian Wildlife Protection Act, 1972.

The phenotypic appearance of the head of animal species depends strongly on the shape of the skull (Kunzel et al., 2014). These studies have been undertaken in many domestic species such as the dog (Onar \& Gunes, 2003; McGreevy et al., 2004), cats (Kunzel et al.) and goats (Olopade \& Onwuka, 2004, 2009a, 2009b) in an attempt to provide baseline anatomic information. The skull has also been used as a major skeletal structure to determine taxonomic affiliations as it is subject to phenotypic changes because of selective breeding (Brüenner et al., 2002). The occipital bone is frequently studied in procedures of sex determination in forensics or anthropology (Rogers, 2005).

The aim of this study is to investigate morphological and radiographic characteristics of the skull of Indian blackbuck, thereby making a contribution in filling the gap of knowledge in this field. The knowledge of morphological characteristics of skull is of great

\footnotetext{
* Teaching Associate, Department of Veterinary Anatomy, Post Graduate Institute of Veterinary Education and Research, Jaipur, India.

${ }^{* *}$ Professor, Department of Veterinary Anatomy, College of Veterinary and Animal Science, G.B. Pant University of Agriculture and Technology, Pantnagar, India.
} 
importance for surgical treatment of pathological conditions and taxonomic affiliation. As per knowledge, in many vetero-legal cases, one fails to identify the bones of this animal and blur them with those of some other small ruminants. This investigation will be helpful to the field veterinarians as well as zoo veterinarians.

\section{MATERIAL AND METHOD}

The present study was conducted on six skulls of adult Indian Blackbuck (Antilope cervicapra) of either sex. The permission for the specimen collection was sought from the Deputy Inspector General (WL), Ministry of Environment and Forests (MoEF), New Delhi, INDIA and the Principal Chief Conservator of Forest (PCCF), Government of Rajasthan. The skeletons were collected from the Jodhpur zoo after official approvals from the Principal Chief Conservator of Forest (PCCF) vide letter no. F, 3 (02) Tech-II/CCF/2010/714 dated 07.05.2014. The skeletons were dug out from the graveyards located in the premises of Jodhpur zoo. The skulls were macerated using the hot water maceration technique of Olopade \& Onwuka (2004) and modified by the authors by adding potassium hydroxide to the boiling process, which was performed at $100{ }^{\circ} \mathrm{C}$ for at least $50 \mathrm{~min}$ and followed by further boiling in water for another 30-40 min after careful separating the mandibles from the skulls (Choudhary \& Singh, 2015). The radiographs were taken from the Department of Veterinary Surgery and Radiology, College of Veterinary and Animal Sciences, G.B. Pant University of Agriculture and Technology, Pantnagar. Subsequently, these osteological specimens were studied to record their gross morphological features.

\section{RESULTS AND DISCUSSION}

The skull comprised of two essential parts- the cranial (Ossa cranii) and the facial (Ossa faciei). The number of skull bones was thirty two of which there were eleven cranial (three single and four paired) and twenty one facial (one single and the rest were paired) bones. The bones of the cranium were occipital, sphenoid, ethmoid, interparietal, parietal, frontal and temporal. The facial bones were maxilla, incisive (premaxilla), palatine, pterygoid, nasal, lacrimal, zygomatic (malar), turbinates, vomer, mandible and hyoid as also reported by Raghavan (1964) in ox, Miller et al. (1964) in dog, Sisson (1964) in ruminants, Getty (1975) in horse and Singh (1984) in camel.

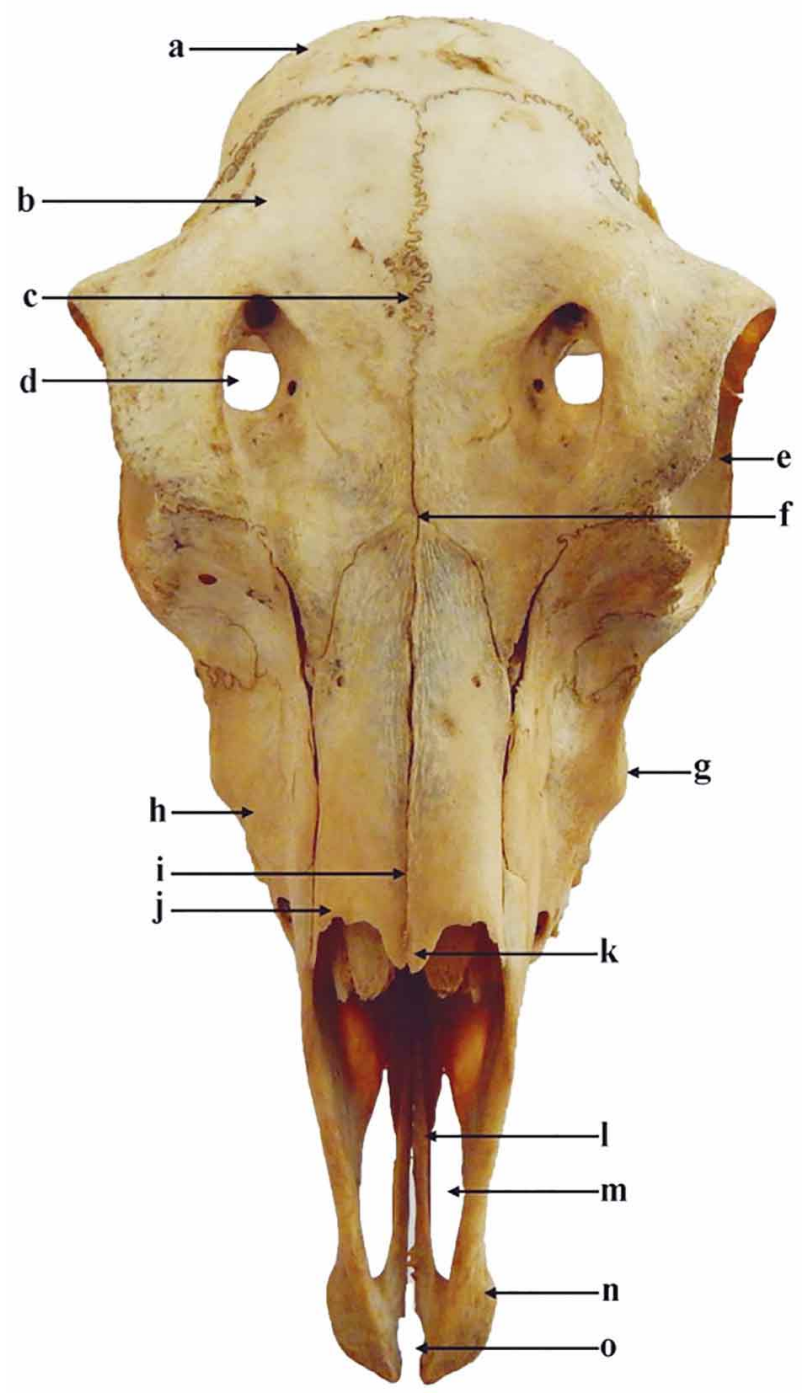

Fig. 1. Dorsal view of the skull of female blackbuck showing parietal bone (a), frontal bone (b), zig-zag interfrontal suture (c), supraorbital foramen (d), orbit (e), fronto-nasal suture (f), facial tuberosity (g), maxilla bone (h), Internasal suture (i), nasal bone (j), nasal process (k), palatine process of incisive bone (l), palatine fissure (m), incisive bone (n), inter-incisive fissure (o).

\section{Cranial bones}

Occipital bone (Os occipital). The placement of occipital bone (Figs. 1 and 6) in blackbuck resembled that of horse (Getty), camel (Singh), dog (Miller et al.) and leopard cat (Sarma et al., 2001). The nuchal surface of the skull was formed by the occipital bone as reported in dog (Miller et $a l$. ) and in horse (Getty); whereas in ox (Raghavan), occipital bone formed the ventral part of nuchal surface. The temporal bone also participated in the formation of the crest, lateral to the paramastoid process as described in camel (Singh). 


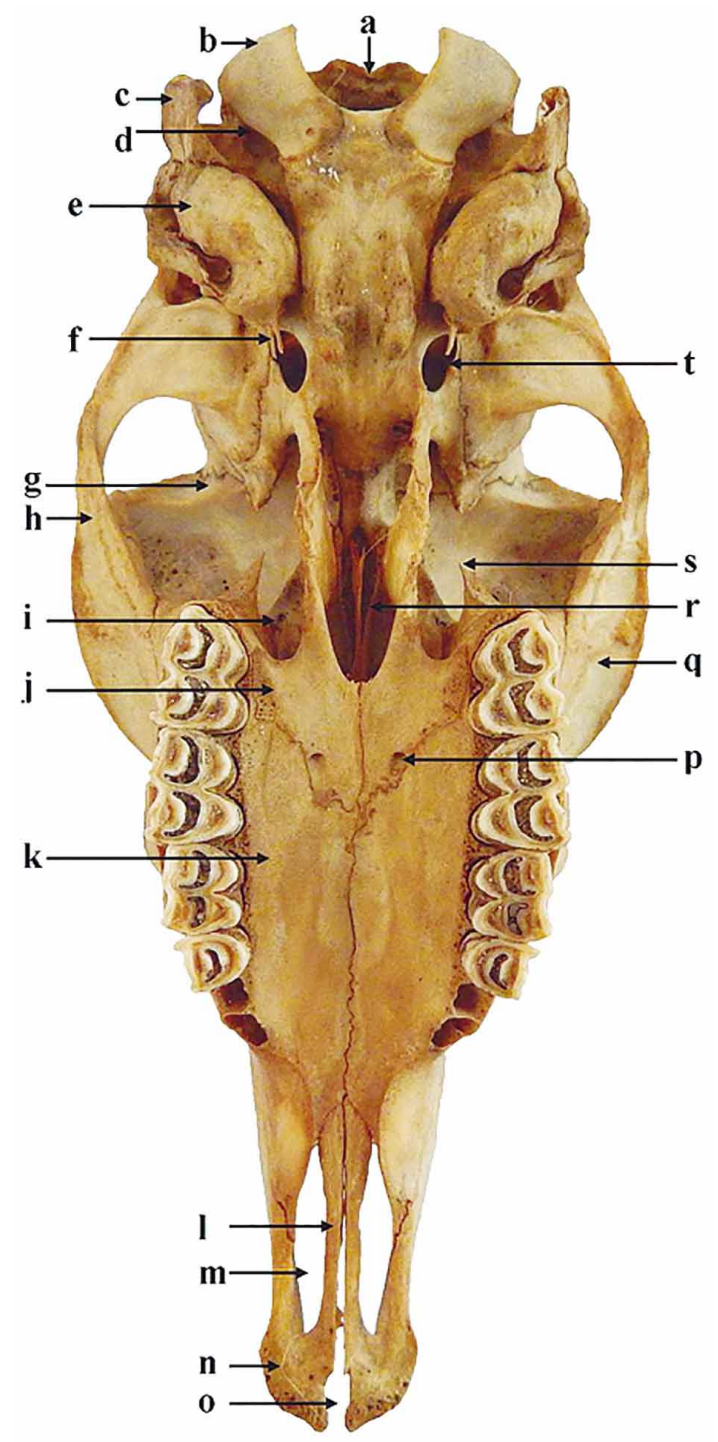

Fig. 2. Ventral view of the skull of female blackbuck showing foramen magnum (a), occipital condyle (b), paracondylar process (c), jugular foramen (d), tympanic bulla (e), muscular process (f), temporal fossa $(\mathrm{g})$, zygomatic arch (h), spehno-palatine foramen (i), horizontal plate of palatine bone (j), palatine process of maxilla (k), palatine process of incisive bone (l), palatine fissure (m), incisive bone (n), incisive fissure (o), major palatine foramen (p), maxilla (q), vomer (r), pterygoid (s), oval foramen (t).

Fig. 4. Dorso-lateral view of the skull of female blackbuck showing parietal bone (a), frontal bone (b), orbit (c), supraorbital foramen (d), lacrimal bulla (e), Fronto-nasal suture (f), nasal bone (g), infraorbital foramen (h), nasal process (i), incisive bone (j), alveolar socket for incisor teeth (k), mental foramen (l), pre molar (m), maxilla bone (n), molar (o), zygomatic arch (p), temporal fossa (q), oval foramen $(r)$, paracondylar process (s), external acoustic meatus $(\mathrm{t})$, temporal bone $(\mathrm{u})$.

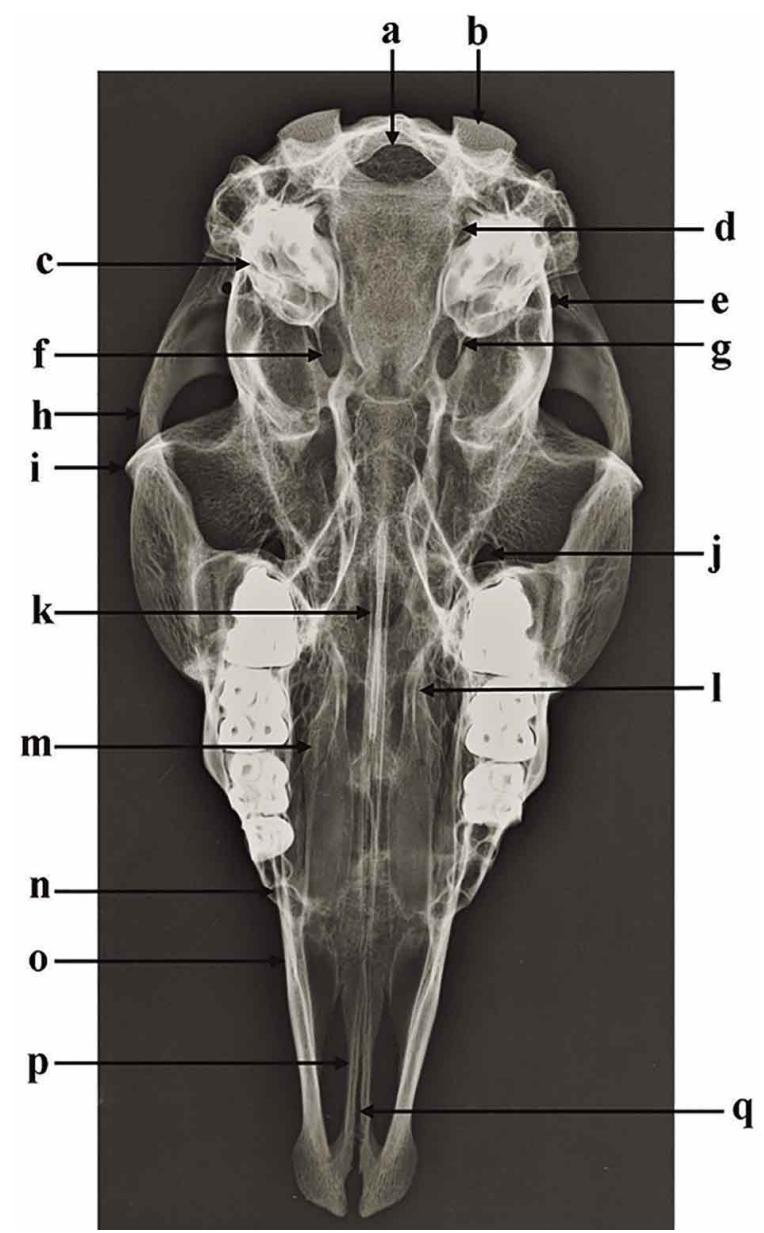

Fig. 3. Radiograph of the skull of blackbuck showing foramen magnum (a); occipital condyle (b); tympanic bullae (c); jugular foramen (d); foramen (e); oval foramen (f); muscular process (g); zygomatic process (h); frontal crest (i); supra-orbital foramen (j); vomer $(\mathrm{k})$; turbinates $(1, \mathrm{~m})$; alveolar socket for first premolar $(\mathrm{n})$; premaxilla (o); palatine process of incisive bone (p); incisive fissure (q).

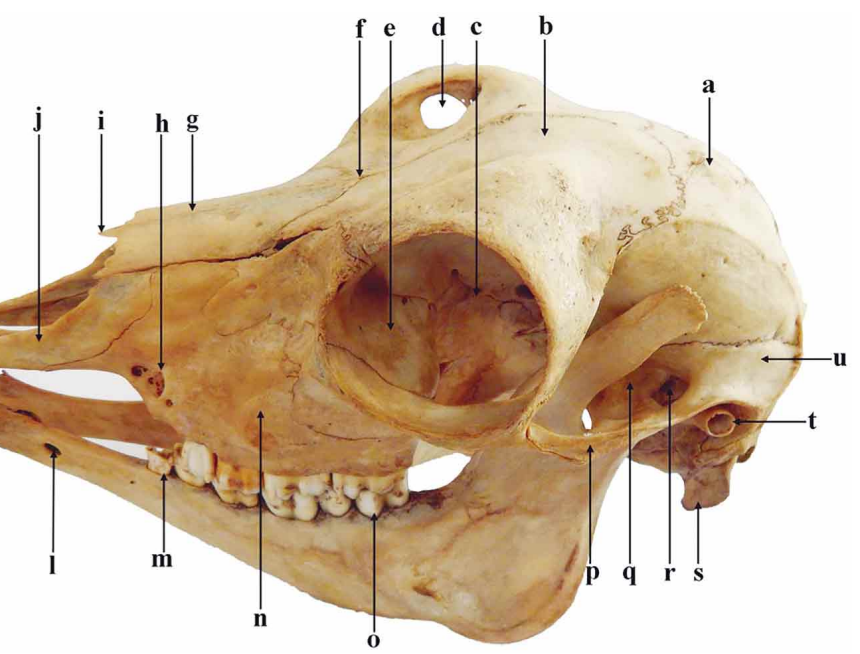


The nuchal surface presented a deep fossa on either side of the external occipital protuberance in rhino (Borthakur \& Bordoloi, 1997). The paramastoid processes or styloid process (Processus jugularis) were thin and prismatic, which projected ventrally as described in chital (Kumawat et al., 2014); whereas the paramastoid process was underdeveloped in arctic foxes (Zuoliang, 2004). These were extremely long in pig (Sarma \& Sarma, 2002) and in tiger they were like strong plates (Joshi, 2004).

The basilar part (Pars basilaris) was short and wide as described in ox (Raghavan) but unlike was the case of camel in which two distinct impressions on the dorsal surface of the basilar part of the occipital bone (Singh). The squamous part (Squama occipitalis) was quadrilateral in blackbuck as reported in camel (Singh) and in horse (Getty) whereas in goat it was pentagonal in shape (Singh \& Patel, 1984). The nuchal crest was less prominent in blackbuck as reported in dog (Miller et al.) and in horse (Getty) than that of tiger (Joshi). The occipital bone consisted of two occipital condyles (Condyli occipitales) as mentioned in ox (Raghavan), horse (Getty), camel (Singh), dog (Miller et al.) and leopard cat (Sarma et al., 2002).

The foramen magnum (Figs. 2, 3 and 6) was large and roughly oval in shape as also reported in ox (Raghavan). However the foramen magnum was almost circular opening in horse (Getty).

Sphenoid bone (Os sphenoidale). The orbital fissure and round foramen unite to form foramen orbitorotundum as mentioned in ruminants (Sisson) and in ox (Raghavan), whereas the orbital fissure and foramen rotundum were separate entities in tiger (Joshi) and in dog (Miller et al.). The oval foramen was formed completely by the sphenoid bone as also reported in sheep (Sisson) and slightly rostral in comparison to the position in ox (Raghavan).

Ethmoid bone (Os ethamoidale). The ethmoid bone was placed between the cranial and nasal cavity as reported in ox (Raghavan), in horse (Getty) and in yak (Archana et al., 1998a). Caudally, the ethmoid bone was fused with the pre sphenoid, rostro-ventrally with vomer and palatine and dorso-rostrally with the frontal bones as described in ox (Raghavan), in horse (Getty) and in yak (Archana et al., 1998a). It consisted of cribriform plate (Lamina cribrosa), labyrinth and perpendicular plate as documented in ruminants (Sisson), in ox (Raghavan) and in yak (Archana et al., 1998a). There was an ethmoidal foramen (Foramen ehamoidale) as reported in ox (Raghavan), in horse (Getty) and in yak (Archana et al., 1998a); however, there were two ethmoidal foramina in dog (Miller et al.) but the foramen was not remarkable as reported in camel (Singh). As mentioned by
Nickel et al. (1973) and Sisson in ruminants, the ethmoidal foramen was situated above and in front of optic canal, but it was present in the orbital plate of the frontal bone which had been reported to be present in horse (Nickel et al.).

Interparietal bone. The Interparietal bone was small quadrilateral wedged in between the parietal anterio-laterally and the supraoccipital posteriorly as described in goat (Singh \& Patel). The interparietal bone had been reported to be present in horse (Getty), in dog (Miller et al.), in ox (Raghavan), in goat (Singh \& Patel). The interparietal process of occipital represented the paired interparietal bone in blackbuck while in dog it was fused prenatally with the supraoccipital (Miller et al.). It was centrally placed between the squamous part of the occipital and parietal bones; but not well recognized due to fusion with the same bone of the opposite side in horse (Getty), in tiger (Joshi).

Parietal bone. The parietal (Fig. 2) was paired bones which formed the caudo-dorsal and lateral walls of the cranial cavity as reported in yak (Archana et al., 1998c), in horse, in dog (Miller et al.) and in chital (Kumawat et al.). In contrast the parietals did not enter into the formation of roof of the cranial cavity in ox (Raghavan) and formed only the dorsal part of the caudal wall of the cranium. The dorsal part contained the extension of the frontal sinus as was also reported in yak (Archana et al., 1998c) and in ox (Raghavan).

Frontal bone. In frontal bone, the caudal part of external surface was strongly convex in blackbuck while the cranial part was suppressed as reported in chital (Kumawat et al.). The frontal bone (Figs. 1 and 4) was much convex as compared with the parietal and nasal bones in adult sloth bear (Kalita et al., 2006) whereas the external surface was slightly convex and smooth in small ruminants and cats (Nickel et al.). The supra-orbital foramen (Fig. 1) was present in the supraorbital groove of the medial margin of the orbit as described in ox (Raghavan). The supraorbital foramen was absent in arctic foxes (Zuoliang), in tiger (Joshi), in adult sloth bear (Kalita et al., 2006) and in dog (Miller et $a l$. .). The supra-orbital foramen perforated the root of the zygomatic process as reported in horse (Getty). According to Raghavan, it may often be double in horse. The supraorbital foramen was closer to the orbital margin than to median line (Inter frontal suture) in goat (Singh \& Patel). The supra-orbital foramina were two to three in number, with a very deep supraorbital groove in Sambar deer and it was in the form of a deep fissure, at the rostro-lateral margin of the orbit in camel (Shahid \& Kausar, 2005). The frontal sinus was confined to the frontal bone as documented by Nickel et al. in small ruminants and horse and El-Gendy \& Alsafy (2010) in donkey, it also occupied the parts of the parietal, interparietal, temporal and occipital bones in ox (Nickel et al.). 
The nasal bone (Figs. 1, 4 and 5) was articulated anteriorly with incisive bone as also reported in $\operatorname{dog}$ (Miller $e t$ $a l$.), in horse (Getty), in chital (Kumawat et al.) and in tiger (Joshi) while the nasal bones articulated with lacrimal bones in ox (Raghavan) and in camel (Singh). The nasal bone formed the greater part of a roof of nasal cavity as reported in tiger (Joshi). It was narrower anteriorly in blackbuck unlike in dog (Miller et al.) where it was wider anteriorly. The anterior extremity was concave and posterior extremity was pointed as reported in dog (Miller) while in ox it was divided into two similar processes by a deeper notch (Raghavan). The posterior extremity of nasal bone was received by a notch formed by the anterior part of frontal bones; this anatomical feature resembled to that of ox (Raghavan) and dog (Miller et al.); dissimilar findings to these were reported in horse (Getty) and camel (Singh) in which the diverging posterior extremities of two nasal bones formed a notch which reciprocated with the small triangular projection formed by the nasal part of two frontal bones. Whereas the nasal bone projected dorsally like a cone into the notch of the frontal bones and rostrally it was divided into two processes, the medial being longer and forming a cone like projection as described in yak (Archana et al., 1997).

The ethmoidal foramen was formed through the concurrence of the orbital part of frontal bone and presphenoid wing as reported in horse (Getty); whereas it was located entirely in the frontal bone in ox (Raghavan); whereas in tiger the ethmoidal foramen was situated at the junction with sphenoid bone (Joshi). Two ethmoidal foramina were commonly present and were formed entirely in frontal bone (Sisson) in dog whereas Miller et al. reported that smaller of these was in the fronto-sphenoid suture and the larger foramen was located dorso-caudal to the smaller and passes obliquely through the orbital portion of the frontal bone.

Temporal bone. The temporal bone constitutes the greater portion of the lateral wall of the cranium. It was situated between the occipital behind, the parietal above, the frontal in front, and the sphenoid below as described by Raghavan in ox, Miller et al. in dog, Sisson in ruminants, Getty in horse and Singh in camel. It was formed by two distinct parts, the squamous and petrous. The squamous temporal was shell like plate and the petrous temporal was placed between the occipital behind and the parietal in front, overlapped externally by the squamous temporal as elucidated in ox (Raghavan) and in chital (Kumawat et al.). The petrous and tympanic parts of temporal bone were united by the occipito-tympanic suture as reported in chital (Kumawat et al.) but was unlike in ox and horse (Nickel et al.). The articular tubercle was absent in blackbuck as mentioned in dog (Miller et al.) and in tiger (Joshi); while it was indistinct in ruminants (Sisson). The hyoid process was short rod shaped which was projected downward and forward below the external auditory process as reported in ox (Raghavan). The mastoid process was absent in blackbuck as described in camel (Singh) and in ox (Raghavan); whereas mastoid process was in the form of a small nodule in tiger (Joshi), while in small ruminants the process was not more than a roughened area (Nickel et al.). However, it was well developed in dog (Miller et al.). The tympanic bulla was large similar to that of camel (Singh) and ox (Raghavan). It articulated with the basilar part of occipital bone similar to $\operatorname{dog}$ (Miller et al.). The temporal fossa was deep and extensive as distinguished by Sharma (2006) in kagani goat; whereas it was described to be wider in ox (Raghavan).

\section{Facial bones}

Maxilla: The facial tuberosity (Fig. 1) was located just caudal to the infra-orbital foramen (Foramen infraorbitale) as reported in ox (Raghavan). The facial or zygomatic crest (Crista facialis) extended caudally from it on to the facial surface of the zygomatic bone in blackbuck which as described in ox (Raghavan). Whereas the facial tuberosity and facial crest were absent in leopard cat (Sarma et al., 2001) and in tiger (Joshi), but in horse (Getty) only the facial tuberosity was absent. The facial crest in horse was more or less parallel to the alveolar margin and its anterior end was about $3-4 \mathrm{~cm}$ dorsal to the $3^{\text {rd }}$ or $4^{\text {th }}$ cheek tooth (Getty). However, Miller $e t$ al., had neither mentioned the facial tuberosity nor facial crest in dog. At that place no maxillary tuberosity and facial crest was observed in camel (Shahid \& Kausar).

Premaxilla (Ossa incisiva). The premaxilla was a thin, wide plate, bent as to form a wide deep groove looking forward (Figs. 1 and 4) as mentioned by Raghavan in ox; whereas in tiger (Joshi) the body was very thick.It had not presented any alveolus in blackbuck as reported in ox (Raghavan), whereas in tiger (Joshi) three alveoli presented for upper incisor. The nasal process (Processus nasalis) was found to be articulated with the nasal bone as reported in horse (Getty) and in dog (Miller et al.) whereas dissimilar to that of arctic foxes (Zuoliang) in which the nasal process was well-developed. The palatine process (Processus palatinus) was a thin plate which forms the anterior part of basis of hard palate as also reported in ox (Raghavan).

Palatine bone (Ossa palatina). The horizontal plate of palatine bone was narrow (Fig. 2) as also described in horse (Getty); it was extended in ox (Raghavan), in dog (Miller et al.) and in tiger (Joshi). The dorsal margin presented sphenopalatine foramen instead of sphenopalatine notch as reported in ox (Raghavan). The major palatine foramina were located entirely on palatine bone as also reported in ox (Raghavan), in dog (Miller et al.), in horse (Getty). Contrary to this, foramen was found entirely on the palatine process of maxilla in camel (Singh). 
Pterygoid bone (Ossa pterygoidea). The pterygoid bone was a flat bone, which was inserted between the sphenoid and perpendicular part of the palatine bone as elucidated by Raghavan in ox, Miller et al. in dog, Joshi in tiger and Nickel et al., in pig and ruminants.

Nasal bone (Ossa nasalia). The nasal bone (Figs. 1, 4 and 5) was articulated anteriorly with incisive bone, as also reported by Miller et al. in dog, Getty in horse and Joshi in tiger while the nasal bones articulated with lacrimal bones in ox (Raghavan) and in camel (Singh).

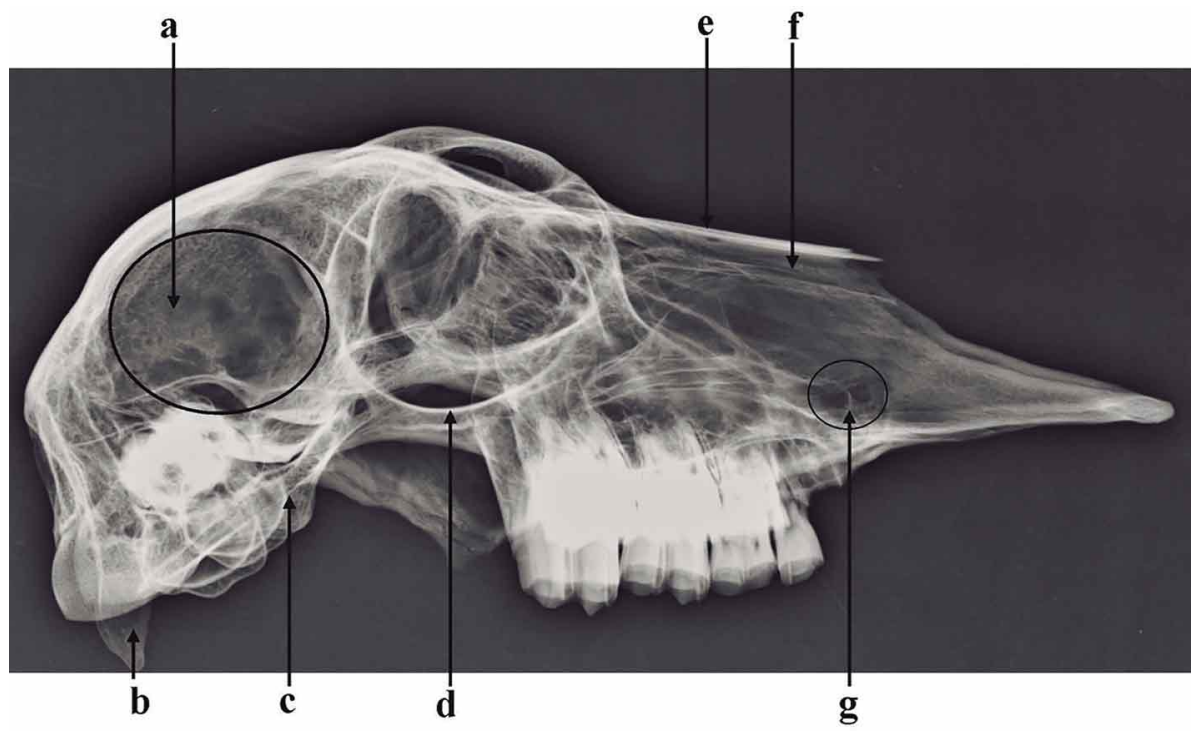

Fig. 5. Radiograph of lateral view of the skull of blackbuck showing cranial cavity (a); paracondylar process (b); temporal bone (c); orbit (d); nasal bone (e); turbinates (f); infraorbital canal and infraorbital foramen $(\mathrm{g})$.
The nasal bone formed the greater part of a roof of nasal cavity as reported in tiger (Joshi). It was narrower anteriorly in blackbuck unlike in dog (Miller et al.) where it was wider anteriorly. The anterior extremity was concave and posterior extremity was pointed as reported in dog (Miller et al.) while in ox it was divided into two similar processes by a deeper notch (Raghavan). The posterior extremity of nasal bone was received by a notch formed by the anterior part of frontal bones; this anatomical feature resembled to that of ox (Raghavan) and dog (Miller et al.); dissimilar findings to these were reported in horse (Getty)

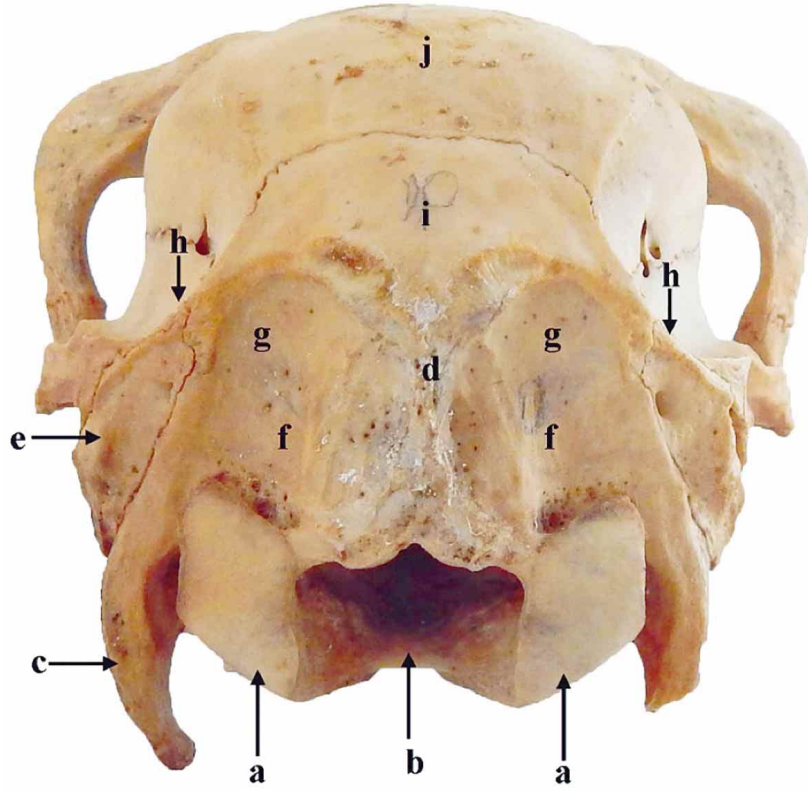

Fig. 6. Nuchal view of skull showing occipital condyle (a); foramen magnum (b); paracondylar process (c); sagittal crest (d); petrous part of temporal bone (e); dorso-condylar fossa (f); squamous part of occipital bone (g); nuchal crest (h); occipital bone (i); parietal bone (j).

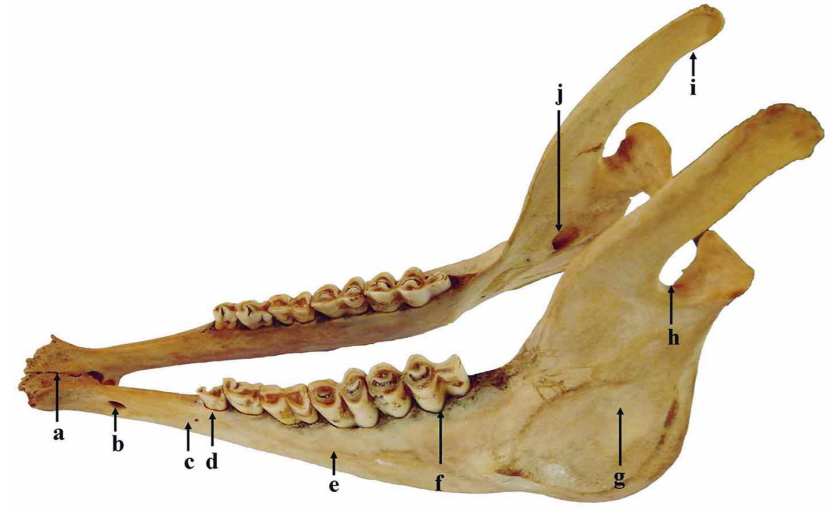

Fig. 7. Dorso-lateral view of the mandible of blackbuck showing alveolar sockets for incisors (a), mental foramen (b), anterior border of ramus (c), first premolar (d), horizontal part of ramus (e), molar (f), posterior border of ramus (g), vertical part of ramus (h), coronoid process (i), mandibular foramen (j). 
and camel (Singh) in which the diverging posterior extremities of two nasal bones formed a notch which reciprocated with the small triangular projection formed by the nasal part of two frontal bones. Whereas the nasal bone projected dorsally like a cone into the notch of the frontal bones and rostrally it was divided into two processes, the medial being longer and forming a cone like projection as described in yak (Archana et al., 1997).

Lacrimal bone (Ossa lacrimalia). The lacrimal bone articulated with frontal bone superiorly, maxilla bone ventrally (Fig. 4), malar bone posteriorly and the palatine bone below and behind; whereas in tiger it articulated with frontal, maxilla and palatine bones (Joshi), in camel with frontal, maxilla and zygomatic (Singh), in horse with nasal and palatine (Getty), in ox with nasal (Raghavan) and in dog with palatine bones in addition to frontal, maxilla and zygomatic (Miller et al.). It's larger and smaller parts along the orbital rim were fused with each other in blackbuck as reported in horse (Getty) and in ox (Raghavan) except for the lacrimal fissure present in blackbuck. Whereas it's facial surface was covered by maxilla in its largest part and very small part along the orbital rim as mentioned in camel (Singh) and in dog (Miller et al.). A lacrimal bulla was present on each side in blackbuck as mentioned in ox (Raghavan); whereas in tiger (Joshi), horse (Raghavan) and camel (Singh) lacrimal bulla was absent. The lacrimal bone was marked by a very prominent depression for the lodgement of the infra-orbital gland in sambar deer (Archana et al., 2003).

Zygomatic bone (Ossa zygomatica). The zygomatic bone was curved crest around the infra-orbital margin, continuous on to the maxilla as mentioned in horse (Getty) and in ox (Raghavan) whereas it was absent in tiger (Joshi). The orbital surface (facies orbitalis) was smaller than the lateral surface (Facies lateralis) as mentioned in horse (Getty) and ox (Raghavan). Its frontal process articulated with the zygomatic process of frontal bone, as mentioned by Raghavan in ox while in the case of horse (Getty) this articulation was absent.

Vomer. The vomer (Fig. 2) was firmly fused with the incisive, maxilla and sphenoid bones, but did not articulate with the palatine bone, as described by Raghavan in ox and Joshi in tiger; whereas the anterior 2/3rd of the its ventral margin fitted into the nasal crests of palatine and the maxilla and only posterior one third was free in horse (Getty). The rostral one third part of the vomer was fitted into the nasal crests of the maxilla to ventral margin as mentioned in ox (Raghavan).

Turbinale bones (Ossa turbinata). The turbinates (Figs. 3 and 5) were delicate, scroll-like, complex bony plates, placed vertically in the nasal cavity, been attached to the lateral walls of the nasal cavity. There were two dorsal turbinates and two ventral on each side of the nasal cavity as described in ox (Raghavan); whereas turbinates were little, delicate spiral bones in dinosaurs (Morell, 1996).

Mandible (Mandibula). The mandibular symphysis (Fig. 7) remained unossified in adult blackbuck as reveled in ox (Raghavan), in dog (Miller et al.) and in spotted deer (Kumawat et al.); Whereas in contrast to this, in camel (Singh) and horse (Getty) the mandibular symphysis was completely ossified.

The horizontal part of the ramus (Pars molaris) of the mandible was slightly curved, when it was located on a flat surface, it did not touch the surface at both ends. The incisive parts of the body remain lifted from the ground as noticed by Singh in camel, Raghavan in ox whereas in tiger it was straight and when it was placed on a flat surface, it touched the surface at both ends (Joshi).

The body in its alveolar margin (Limbus alveolaris) presented three incisor teeth and one canine on each side as reported in leopard (Ray et al., 1997; Kalita et al., 2001) and in tiger (Joshi). The molar part of the body presented alveoli for six cheek teeth (three premolar teeth and three molar teeth) in blackbuck as reported in leopard (Sarma $e t$ al., 2002), horse (Getty), ox (Raghavan) and yak (Archana et al., 1998c). The alveolar margin of the incisive part of the body presented eight alveoli for incisors as noted in blackbuck (Kumawat et al.).

On lateral surface behind the base of the canine tooth, only one mental foramen (Foramen mentale) was present as reported in horse (Getty), in ox (Raghavan), in yak (Archana et al., 1998b), in rhinoceros (Bordoloi et al., 1995) and in spotted deer (Kumawat et al.). However in tiger (Joshi), camel (Singh) and dog (Miller et al.) there were three mental foramina. However, according to Ray et al. and Kalita et al. (2001), there were two mental foramina in leopard.

The molar part diverged caudo-laterally from the incisive part to enclose the "V" shaped inter-mandibular space as reported in carnivores (Getty; Nickel et al.), in ruminants (Sisson), in yak (Archana et al., 1998b), in rhinoceros (Bordoloi et al.) and in tiger (Joshi).

The mandibular tuberosity was not observed as noted in leopard (Kalita et al., 2001), in horse (Getty), in ox (Raghavan), in dog (Miller et al.), in tiger (Joshi) and in spotted deer (Kumawat et al.). However, a tubercle had been reported in camel (Singh) and in rhinoceros (Bordoloi et al.) but it was well developed in yak (Archana et al., 1998b). 
The ventral margin of ramus was convex in its length as described in dog (Miller et al.), in ox (Raghavan) and in yak (Archana et al., 1998b). However in tiger (Joshi) ventral margin of mandible was thick, straight and slightly rounded, in leopard (Kalita et al., 2001) and in young horses (Getty) it was thick, rounded and nearly straight, but it became narrower and sharp in older horses (Getty). The alveolar margin was slightly concave in blackbuck as reported in leopard (Kalita et al., 2001), while it was almost straight in camel (Singh).

The vertical part of ramus was the non-tooth bearer, expanded vertical part of the mandible as revealed in carnivores (Nickel et al.), in yak (Archana et al., 1998b) and in leopard (Kalita et al., 2001).

On the lateral surface of ramus was present a rough area in blackbuck as described in spotted deer (Kumawat $e t$ $a l$.). There was a big triangular rough fossa in tiger (Joshi). It was concave and roughened in camel (Singh), but it was not present rough lines in blackbuck as reported in horse (Getty) and in ox (Raghavan).

The articular extremity (caudal extremity) was composed of condylar process and coronoid process with the intervening notch as described in ox (Raghavan), in yak (Archana et al., 1998b), in leopard (Kalita et al., 2001), in rhinoceros (Bordoloi et al.) and in spotted deer (Kumawat et al.). The coronoid process curved caudally and extended caudo-dorsally above the condyle to form the highest point of the bone as also reported in leopard (Kalita et al., 2001) and in yak (Archana et al., 1998b). The head of the condylar process was elongated transversely as described in camel (Singh), in ox (Raghavan), in tiger (Joshi) and in spotted deer (Kumawat et al.).

Hyoid bone (Os hyoideum): The hyoid bone was situated between the vertical parts of the rami of the mandible as elucidated in ox (Raghavan) and in horse (Getty). It was attached to the petrous part of temporal bone by rods of cartilages as reported in ox (Raghavan) and in horse (Getty). The lingual process were short and tuberous as reported in ox (Raghavan), but in disagreement with the reports of Getty in horse, where lingual process was compressed laterally and had blunt-pointed free ends; while lingual process was absent in dog (Miller et al.). The thyroid cornua was compressed laterally and not fused with the body as reported in ox (Raghavan); while thyroid cornua was fused in horse (Getty) and dog (Miller et al.). The small cornua were short rods which were directed upward and forward form either end of the upper surface of the body as reported in ox (Raghavan) and in horse (Getty).

\section{ACKNOWLEDGEMENTS}

The authors are grateful to the Ministry of Environment of Forests (MoEF), New Delhi and Jodhpur Zoo for providing necessary facilities and support for carrying out research on the bones of blackbuck. The funding was provided by the Department of Science and Technology, New Delhi, India as Ph.D. grant (DST-INSPIRE Fellowship) to the first author.

CHOUDHARY, O. P. \& SINGH, I. Estudios morfológicos y radiográficos del cráneo del antílope negro (Antilope cervicapra) de la India. Int. J. Morphol., 34(2):775-783, 2016.

RESUMEN: La apariencia fenotípica de la cabeza de las especies animales depende principalmente de la forma del cráneo. El objetivo fue estudiar las características morfológicas y radiográficas del cráneo del antílope negro de la India. El cráneo consta de los huesos craneales y faciales. Los huesos craneales incluyen occipital, esfenoides, etmoides, interparietal, parietal, frontal y temporal. El occipital es un hueso singular que circunda el foramen occipital. El esfenoides se sitúa entre el occipital posterior y el etmoidal anterior. El etmoidal es un hueso singular situado de forma ventral a los huesos frontal y nasal. El interparietal es un pequeño hueso cuadrilátero ubicado entre el parietal anterolateral y posterior del supraoccipital. El parietal es un hueso bilateral. El hueso bilateral frontal cubría la cavidad craneal. El hueso occipital era más o menos de forma pentagonal. El hueso temporal formaba parte de la pared lateral de la cavidad craneal. Los huesos faciales incluyen el hueso maxilar, premaxila, palatina, pterigoideo, nasal, lacrimal, cigomático, vómer, conchas nasales, mandíbula y el hueso hioides. El maxilar se presentó como un hueso bilateral plano más o menos triangular. Los huesos incisivos estaban colocados en la parte inferior de la cara. El hueso palatino es un hueso bilateral. El hueso pterigoideo bilateral, plano pequeño, de hueso y situado a ambos lados de las fosas posteriores. El hueso nasal en ambos lados formaba la cubierta de la cavidad nasal. El lagrimal es un hueso asociado y situado en el margen anterior de la órbita. El cigomático es un hueso irregular de contorno triangular. El vómer esun solo hueso medial. La concha nasal delgada con forma de espiral, placas óseas complejas y colocadas verticalmente en la cavidad nasal unidas a las paredes laterales. La mandíbula es un hueso bilateral. El hueso hioides estaba situado entre las partes verticales de las ramas de la mandíbula.

PAlabras CLAVE: Antílope negro; Cráneo; Morfológia; Radiográfia; Craneal; Huesos faciales.

\section{REFERENCES}

Archana; Sudhakar, L. S. \& Sharma, D. N. The anatomy of nasal bone (Os nasale) of yak (Bos grunniens). Indian J. Vet. Anat., 9(1-2):413, 1997. 
Archana; Sudhakar, L. S. \& Sharma, D. N. Anatomy of the ethmoid bone of yak (Bos grunniens). Indian J. Vet. Anat., 10(1-2): 21-5, 1998a.

Archana; Sudhakar, L. S. \& Sharma, D. N. Anatomy of the mandible of yak (Bos grunniens). Indian J. Vet. Anat., 10(1-2):16-20, $1998 \mathrm{~b}$.

Archana; Sudhakar, L. S. \& Sharma, D. N. Anatomy of the parietal and interparietal bones of yak (Bos grunniens). Indian J. Vet. Anat., 10(12):26-30, 1998c.

Bordoloi, C. C.; Borthakur, S.; Talukdar, S. R.; Kalita, S. N.; Baishya, G. \& Kalita, H. Mandible of the great Indian one-horned rhinoceros (Rhinoceros unicornis). Indian Vet. J., 72:838-42, 1995.

Borthakur, S. \& Bordoloi, C. C. Gross anatomical study on the skull of adult rhino (Rhinocerous unicornis). Indian Vet. J., 74:670-2, 1997.

Brüenner, H.; Lugon-Moulin, N.; Balloux, F.; Fumagalli, L. \& Hausser, J. A taxonomical re-evaluation of the Valais chromosome race of the common shrewSorex araneus (Insectivora: Soricidae). Acta Theriol., 47(3):245-75, 2002.

Choudhary, O. P. \& Singh, I. Morphometrical studies on the skull of Indian Blackbuck (Antelope cervicapra). Int. J. Morphol., 33(3):868-76, 2015.

El-Gendy, S. A. A. \& Alsafy, M. A. M. Nasal and paranasal sinuses of the donkey: Gross anatomy and computed tomography. J. Vet. Anat., $3(1): 25-41,2010$.

Getty, R. Sisson and Grossman's: The Anatomy of the Domestic Animals, $5^{\text {th }}$ edition, Volume 1. Philadelphia, WB Saunders, 1975.

Joshi, H. Gross Anatomical Studies of the Skull of Indian Tiger (Panthera tigris). Thesis M.V.Sc. Bikaner, Rajasthan Agricultural University, 2004.

Kalita, A.; Sarma, M.; \& Sharma, K.K. Anatomy of the mandible of Indian Leopard. Indian Vet. J., 12(78):1138-40, 2001.

Kalita, P. C.; Kalita, H. C. \& Sarma, K. Anatomy of the skull of sloth bear (Melursus ursinus). Indian J. Ani. Sci., 76(3):225-7, 2006.

Kumawat, R.; Joshi, S.; Mathur, R. \& Choudhary, O.P. Gross Anatomical Studies on the Cranial Bones of Skull in Chital (Axis axis). Indian J. Vet. Anat., 26(1):54-5, 2014.

Kunzel, W.; Breit, S. \& Oppel, M. Morphometric investigations of breedspecific features in feline skulls and considerations on their functional implications. Anat. Histol. Embryol., 32(4):218-23, 2014.

McGreevy, P.; Grassi, T. D. \& Harman, A. M. A strong correlation exists between the distribution of retinal ganglion cells and nose length in the dog. Brain Behav. Evol., 63(1):13-22, 2004

Miller, M. E.; Christensen, G. C. \& Evans, H. E. Anatomy of the dog. Philadelphia, W. B. Saunders Co., 1964.

Morell, V. A Cold, Hard Look at Dinosaurs. Discover, 17(12):98-108, 1996.

Nickel, R.; Schummer, A. \& Seiferle, E. The Viscera of the Domestic Mammals. New York, Verlag Paul Parey, 1973. pp.211-79.

Olopade, J. O. \& Onwuka, S. K. A review of the craniofacial and neurometric anatomy of the goat. Trop. Vet., 27(4):1-19, 2009b.
Olopade, J. O. \& Onwuka, S. K. Morphometric analysis of the skull of the Sahel goat breed: basic and clinical anatomy. Ital. J. Anat. Embryol., 114(4):167-78, 2009a.

Olopade, J. O. \& Onwuka, S. K. Morphometric studies of the cranio-facial region of the West African Dwarf Goat in Nigeria. Int. J. Morphol., 22(2):145-8, 2004

Onar, V. \& Günes, H. On the variability of skull shape in German shepherd (Alsatian) puppies. Anat. Rec. A Discov. Mol. Cell. Evol. Biol., 272(1):460-6, 2003

Raghavan, D. Anatomy of the Ox; with Comparative Notes on the Horse, Dog and Fowl. New Delhi, Indian Council of Agricultural Research, 1964.

Ray, S.; Dutta, G. K. \& Ray, M. Anatomy of the mandible of leopard (Panthera pardus). Indian Vet. J., 74(9):765-7, 1997.

Rogers, T. L. Determining the sex of human remains through cranial morphology. J. Forensic. Sci., 50(3):493-500, 2005.

Sarma, K. \& Sarma, M. Anatomy of the skull of dum pig of Assam. Indian Vet. J., 79(7):708-11, 2002.

Sarma, K.; Nashiruddullah, N. \& Islam, S. Anatomy of the skull of a leopard cat (Felis bengalensis). Indian J. Ani. Sci., 71(11):1011-3, 2001.

Sarma, K.; Sarma, M. \& Nashirudullah, N. Anatomy of the mandible of leopard cat (Felis bengalancis). Indian Vet. J., 79(10):1063-4, 2002

Shahid, R. U. \& Kausar, R. Comparative gross anatomical studies of the skull of one-humped camel (Camelus dromedarius). Pak. Vet. J., 25(4):205-6, 2005

Sharma, K. Morphological and craniometrical studies on the skull of Kagan Goat (Capra hircus) of Jammu Region. Int. J. Morphol., 24(3):44955, 2006.

Singh, J. \& Patel, M. R. The osteology of skull of goat. Indian J. Vet. Sci. Ani. Husb., 8:80-9, 1984.

Singh, P. Gross Anatomical Studies on the Skull of Camel (Camelus dromedarius). Thesis M.V.Sc. Hisar, Haryana Agriculture University, 1984.

Sisson, S. Ruminant Osteology. In: Sisson, S.; Grossman, J. D. \& Getty, R. (Eds.). Sisson and Grossman's The Anatomy of the Domestic Animals. $5^{\text {th }}$ ed. Philadelphia, W. B. Saunder's Co., 1964.

Zuoliang, F. Comparative anatomical studies on the skeleton of arctic foxes. J. Econ. Anim., 8(2):80-4, 2004

Correspondence to:

Dr. Ishwer Singh

Professor, Department of Veterinary Anatomy

College of Veterinary and Animal Science

G.B. Pant University of Agriculture and Technology

Pantnagar-263 145 - INDIA

Received: 06-11-2015

Email: Singh_iswar@yahoo.co.in Accepted: 01-03-2016 dr_om_choudhary@yahoo.co.in 